\title{
Efficacy and safety of immunological checkpoint inhibitors combined with anti-angiogenic drugs in first-line treatment of metastatic renal cell carcinoma: a systematic review and meta- analysis
}

\author{
Yingwei Xie ${ }^{1}$, Zhiliang Chen ${ }^{1}$, Qiyu Zhong ${ }^{1}$, Yuqing Chen ${ }^{2}$, Wentai Shangguan ${ }^{1}$, Wenlian Xie ${ }^{1}$ \\ ${ }^{1}$ Department of Urology, Sun Yat-sen Memorial Hospital, Sun Yat-sen University, Guangzhou, Guangdong, China; ${ }^{2}$ Department of Pathology, Sun \\ Yat-sen Memorial Hospital, Sun Yat-sen University, Guangzhou, Guangdong, China \\ Contributions: (I) Conception and design: Y Xie, W Xie; (II) Administrative support: W Xie; (III) Provision of study materials or patients: W \\ Shangguan; (IV) Collection and assembly of data: Z Chen, Q Zhong; (V) Data analysis and interpretation: Y Xie, Y Chen; (VI) Manuscript writing: \\ All authors; (VII) Final approval of manuscript: All authors. \\ Correspondence to: Wenlian Xie. 107 Yanjiang West Road, Yuexiu District, Guangzhou 510120, China. Email: xiewl@mail.sysu.edu.cn.
}

Background: Immune checkpoint inhibitors (ICIs) have shown promising results for the second-line treatment of metastatic renal cell carcinoma (mRCC). Several randomized controlled trials have so far also evaluated the efficacy of ICIs for first-line treatment of mRCC. In this study, we conducted a meta-analysis of relevant studies to further clarify the efficacy and safety of ICIs combined with anti-angiogenic drugs for the treatment of mRCC.

Methods: We searched the PubMed, Embase, and Cochrane libraries for RCT trials of ICIs combined with anti-angiogenic drugs for first-line treatment of mRCC published before November 20, 2019. A metaanalysis was conducted based on methodological recommendations by the Cochrane Collaboration.

Results: Four articles with a total of 2,967 patients met the inclusion criteria. Our meta-analysis revealed that progression-free survival (PFS) and objective response rate (ORR) were significantly improved in the experimental group while there was no significant difference in overall survival (OS) (HR 0.75, 95\% CI: 0.67-0.84; HR 1.43, 95\% CI: 1.07-1.91; HR 0.74, 95\% CI: 0.53-1.03). After stratification for PD-L1 expression, OS, PFS, and ORR of PD-L1 positive patients were significantly increased in the experimental group (HR 0.74, 95\% CI: 0.56-0.96; HR 1.66, 95\% CI: 1.11-2.49; HR 0.65, 95\% CI: 0.57-0.75).

Conclusions: Immunological checkpoint inhibitors combined with anti-angiogenic drugs as a first-line treatment for mRCC improve PFS and ORR. This effect is more pronounced in PD-L1 positive patients, where ICIs also improve OS. ICIs do not increase the incidence of adverse events.

Keywords: Immune checkpoint inhibitors (ICIs); anti-angiogenic drugs; renal cancer; meta-analysis

Submitted Jun 04, 2020. Accepted for publication Oct 30, 2020.

doi: 10.21037/tau-20-969

View this article at: http://dx.doi.org/10.21037/tau-20-969

\section{Introduction}

Renal cell carcinoma (RCC) is a common tumor and originates from tubular epithelial cells (1). According to the latest cancer statistics released at CA Cancer 7 Clin in 2016, the number of new cases of renal cancer in China is 66,800 , and the number of deaths was 23,400 , ranking

^ ORCID: 0000-0001-5222-0767. 
15 th and 17 th respectively in population morbidity and mortality (2). Renal cancer is not sensitive to radiotherapy and chemotherapy. For early stage renal cancer, surgical resection is the most effective treatment, but nearly onethird of patients have had distant metastases at the time of diagnosis, and even if they have undergone surgery, $30 \%$ of patients still have tumor recurrence or metastasis (2).

Currently, targeted drug therapy and immunotherapy were used to treat metastatic renal cell carcinoma (mRCC). Molecular targeted drug therapy targeting VEGF, mTOR and other targets had achieved positive results (3). However, the final destination of targeted drug therapy in clinical applications was almost all patients with drug resistance, which leaded to the failure of targeted therapy.

In recent years, immunological checkpoint inhibitors (ICIs) have continued to develop. Inhibitors of programmed cell death protein 1 (PD-1) and its ligand (PD-L1) had shown significant efficacy in the treatment of mRCC. They improved the prognosis of patients after failed targeted therapy and effectively prolong their survival (4). Some studies had shown that anti-angiogenic drugs may have a role in regulating the immune system, and the combination of ICIs will enhance the effectiveness of the latter (5-7). Preliminary clinical trials have shown that combined use of ICIs and anti-angiogenic drugs as first-line therapy can improve progression-free survival (PFS) and objective response rate (ORR) in patients with mRCC (8-11). Thus, in this study, we have performed a meta-analysis of the available evidence in order to assess the efficacy and safety of ICIs combined with anti-angiogenic drugs as first-line therapy for mRCC. We present the following article in accordance with the PRISMA reporting checklist (available at http://dx.doi.org/10.21037/tau-20-969) (12).

\section{Methods}

\section{Literature search}

We searched PubMed, Embase, the Cochrane Library databases, Web of Science and grey literature for studies published before November 20, 2019. Queries were structured as follows: "Nivolumab" or "Pembrolizumab" or "Atezolizumab" or "Avelumab" or "immunological checkpoint inhibitors" or "immunotherapy" or "ICIs" or "anti-PD-L1" and "renal cell cancer" or "renal cell carcinoma" or "kidney tumor". If necessary, we contacted the appropriate authors for more information. The studies we searched included only Phase II or Phase III studies.
Computer searches retrieved review articles, and the main research cited in these articles was manually searched.

\section{Inclusion and exclusion criteria}

The two authors independently screened out each study. If there is any dispute, the decision should be made after consultation with the third author. Studies were included based on the inclusion criteria: English publication; RCT; immunological checkpoint inhibitor combined with anti-angiogenic drugs as the experimental group; firstline metastatic clear cell renal cell carcinoma (mccRCC) participants; The primary outcome was overall survival (OS), PFS, and ORR, and the secondary outcome was adverse events.

The exclusion criteria were as follows: animal studies; non-randomized studies; combination drugs were not antiangiogenic drugs; studies were not first lines of treatment for mRCC.

\section{Data extraction}

We extracted relevant data, including trial name, first author, year of publication, patient characteristics, study design, medication regimen, mean follow-up time, survival outcomes expressed as OS and PFS, ORRs, patients with adverse events total.

\section{Quality assessment}

The Cochrane Collaborative Risk Bias Assessment Tool was used to assess the quality of clinical trials (13). The quality of the study was judged based on five domains (random sequence generation, allocation concealment, outcome evaluation blindness, result data integrity, and selective reporting of research results). The evaluator assessed each study for a low, high, or unclear risk of bias. Low-risk studies in at least three areas are considered at low-risk of bias, while studies in $\leq 2$ low-risk areas are considered to be at some or high risk of bias. The literature quality evaluation was carried out by two authors.

\section{Statistical analysis}

Meta-analysis was performed using the Stata SE12.0 software. Following a heterogeneity test, if $\mathrm{I}^{2}<50 \%$ and $\mathrm{P}>0.1$, a fixed effect model was used for analysis; if $\mathrm{I}^{2}>50 \%$ and $\mathrm{P}<0.1$, a random effect model was used for analysis, and the forest map of the meta-analysis was drawn. 


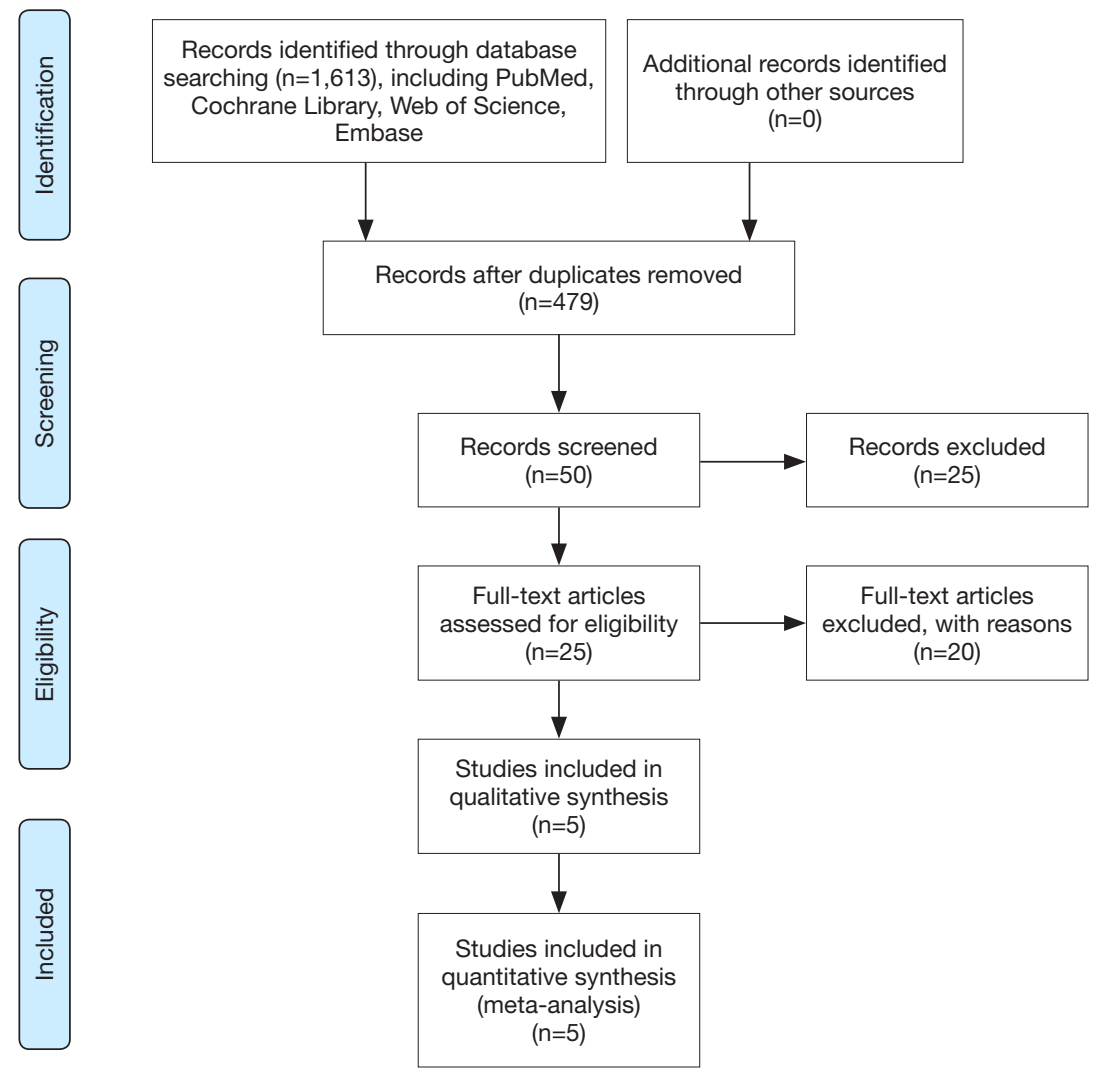

Figure 1 Flow diagram of the study search and selection.

Descriptive analysis was required if the indicators were too heterogeneous or the indicators could not be combined. Categorical variable relationships were analyzed using relative risk (RR) and its 95\% confidence interval (CI). Each study calculated time to event variables, including OS, PFS, and HR with $95 \%$ CI. $\mathrm{P}<0.05$ was considered to be statistically significant. Harbord and Egger tests were used to evaluate the potential publication bias.

\section{Results}

The detailed process of study selection is shown in the flow diagram (Figure 1). A total of 4 studies (8-11) were eventually included in this analysis. Table 1 summarizes the characteristics of these studies. In all studies, sunitinib alone was used in the control group. The Cochrane Collaboration risk bias assessment score was 5 , indicating good quality of the included studies. Due to the small number of trials included, there was no estimate of publication bias.

Based on our research requirements, 51 cases treated with atezolizumab were excluded from the study by
McDermott (8), leaving a remaining total of 2,916 cases in our analysis. The PD-L1 status was assessed in 2,825 patients, of which 1,529 (54.12\%) were positive. Three studies reported OS, 4 studies reported PFS, 4 studies reported ORR, and 4 reported adverse events.

There was no statistically significant improvement in the OS of the experimental group (HR 0.74, 95\% CI: 0.53-1.03, $\mathrm{I}^{2}=75.0 \%$ ) (Figure $2 A$ ). Stratification of patients by PDL1 status revealed that OS was significantly improved in PD-L1 positive patients (HR 0.74, 95\% CI: 0.56-0.96, $\mathrm{I}^{2}=29.5 \%$ ), while the OS was not statistically significant improvement in PD-L1 negative patients (HR 0.80, 95\% CI: $0.53-1.22, \mathrm{I}^{2}=56.2 \%$ ) (Figure $2 B$ ).

PFS was significantly improved in the experimental group (HR 0.75, 95\% CI: 0.67-0.84, $\mathrm{I}^{2}=35.1 \%$ ) (Figure $3 A$ ). When stratifying patients by PD-L1 status, PFS was significantly improved in $\mathrm{PD}-\mathrm{L} 1$ positive patients (HR $0.65,95 \%$ CI: $\left.0.57-0.75, \mathrm{I}^{2}=0.0 \%\right)$ but not in PD-L1 negative patients (HR 0.91, 95\% CI: 0.76 to $1.09, \mathrm{I}^{2}=0.0 \%$ ) (Figure 3B).

ORR was reported in $1,131 / 2,854(39.63 \%)$ patients 
Table 1 Characteristics of the analysed trials

\begin{tabular}{|c|c|c|c|c|c|c|c|c|c|c|}
\hline First author & Item number & $\begin{array}{c}\text { Number of } \\
\text { patients }\end{array}$ & $\begin{array}{c}\text { Cancer } \\
\text { type }\end{array}$ & $\begin{array}{l}\text { Age, } \\
\text { years }\end{array}$ & PD-L1+ & Experimental group & Control group & $\begin{array}{l}\text { Follow-up } \\
\text { time }\end{array}$ & $\begin{array}{l}\text { Evaluation } \\
\text { index }\end{array}$ & $\begin{array}{l}\text { Risk } \\
\text { bias }\end{array}$ \\
\hline $\begin{array}{l}\text { McDermott } \\
2018 \text { (8) }\end{array}$ & IMmotion150 & 305 & $\mathrm{mRCC}$ & 58 & $\mathrm{IHC} \geq 1 \%$ & $\begin{array}{c}\text { Atezolizumab } \\
(1,200 \mathrm{mg})+ \\
\text { bevacizumab } \\
(15 \mathrm{mg} / \mathrm{kg}) \text { every } \\
\text { three weeks, or } \\
\text { atezolizumab } \\
(1,200 \mathrm{mg}) \text { every } \\
3 \text { weeks }\end{array}$ & $\begin{array}{l}\text { Sunitinib } \\
(50 \mathrm{mg} / \mathrm{d}) \text { orally } \\
\text { for four weeks }\end{array}$ & 20.7 & $\begin{array}{l}\text { PFS, ORR, } \\
\text { DOR }\end{array}$ & 5 \\
\hline $\begin{array}{l}\text { Motzer } \\
2019(9)\end{array}$ & $\begin{array}{l}\text { JAVELIN } \\
\text { Renal101 }\end{array}$ & 886 & $\mathrm{mRCC}$ & 62 & $\mathrm{IHC} \geq 1 \%$ & $\begin{array}{c}\text { Avelumab } \\
(10 \mathrm{mg} / \mathrm{kg}) \text { every } \\
2 \text { weeks + axitinib } \\
(5 \mathrm{mg}) \text { twice daily }\end{array}$ & $\begin{array}{l}\text { Sunitinib } \\
(50 \mathrm{mg}) \text { once } \\
\text { daily for } 4 \\
\text { weeks }\end{array}$ & 13.8 & $\begin{array}{l}\text { PFS, OS, } \\
\text { ORR }\end{array}$ & 5 \\
\hline $\begin{array}{l}\text { Rini } \\
2019 \text { (11) }\end{array}$ & IMmotion151 & 915 & $\mathrm{mRCC}$ & 61 & $\mathrm{IHC} \geq 1 \%$ & $\begin{array}{c}\text { Atezolizumab } \\
(1,200 \mathrm{mg})+ \\
\text { bevacizumab } \\
(15 \mathrm{mg} / \mathrm{kg}) \text { once } \\
\text { every } 3 \text { weeks }\end{array}$ & $\begin{array}{l}\text { Sunitinib } \\
(50 \mathrm{mg}) \text { once } \\
\text { daily for } \\
4 \text { weeks }\end{array}$ & 24 & $\begin{array}{l}\text { PFS, OS, } \\
\text { ORR }\end{array}$ & 5 \\
\hline
\end{tabular}

IHC, Immunohistochemistry; PD-L1, programmed death ligand 1; ORR, objective response rate; OS, overall survival; PFS, progression free survival; DOR, duration of overall response; NR, not report.

over the four studies. These included $681 / 1,427$ patients $(47.72 \%)$ in the experimental group, and 450/1,525 patients (29.51\%) in the control group. Three studies reported an ORR in patients with positive PD-L1 expression. We analyzed the ORR and found that it was significantly increased in the experimental group overall (RR 1.43, $95 \%$ CI: $1.07-1.91, \mathrm{I}^{2}=87.9 \%$ ) (Figure $4 A$ ), and also significantly increased in the subgroup of $\mathrm{PD}-\mathrm{L} 1$ positive patients (RR 1.66, 95\% CI: $1.11-2.49, \mathrm{I}^{2}=80.8 \%$ ) (Figure $4 B$ ). These analyses showed that the ORR of ICIs combined with antiangiogenic drugs was 1.43 times that of sunitinib monotherapy overall (1.66 times in PD-L1-positive patients).

Adverse events of grade 3-5 were reported in 1,843/2,825 $(65.23 \%)$ patients in the four analyzed studies. These were reported to have occurred in $880 / 1,415$ patients $(62.19 \%)$ in the experimental group, and $963 / 1,410$ patients $(68.30 \%)$ in the control group. We analyzed the adverse reactions and found no significant difference between the two groups (RR 0.93, 95\% CI: 0.81-1.08, $\mathrm{I}^{2}=85.4 \%$ ) (Figure 5). Two of the assessed studies reported incidents of adverse reactions in detail. We therefore selected the top ten adverse events of grade $\geq 3$ in each group (Table 2). As shown in Table 2, the most common adverse reaction for each group was hypertension.

\section{Discussion}

In recent years, the application of ICIs, such as antiPD-1 or PD-L1 antibodies, has caused about a major breakthrough for the treatment of mRCC (14). In this study, we evaluated immunological checkpoint inhibitors combined with anti-angiogenic drugs for first-line treatment of mRCC. We conducted a meta-analysis of the four relevant studies and found that the combination of ICIs with anti-angiogenic drugs improved PFS and ORR in patients with mRCC. Overall, the OS was not significant difference between the control and experimental groups. Stratification based on PD-L1 expression revealed that addition of ICIs to standard care significantly improved OS, PFS, and ORR in PD-L1 positive patients. In addition, we analyzed adverse events and found no difference between 


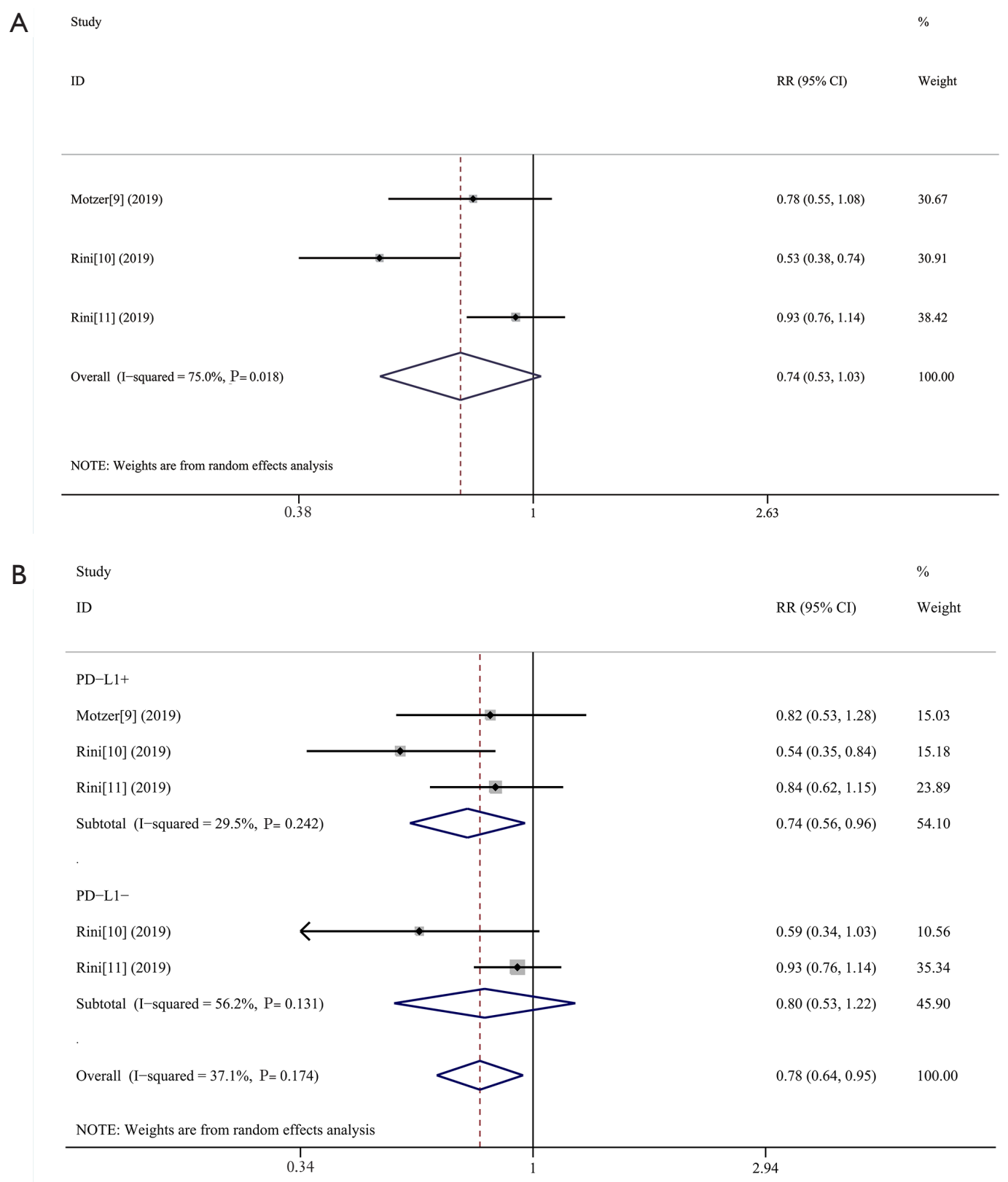

Figure 2 Meta-analysis of HRs for OS comparing ICIs combined with anti-angiogenic drugs and sunitinib. (A) Unselected patients; (B) PDL1 positive and negative patients. HR, hazard ratio; OS, overall survival; ICIs, immune checkpoint inhibitors.

the experimental and control group. This study therefore provides further evidence for the clinical efficacy and safety of ICIs in combination with anti-angiogenic drugs for firstline treatment of mRCC.

Several clinical studies combining anti-angiogenic drugs with checkpoint therapies have reported improvements in tumor immune responses with associated clinical benefits. Bevacizumab and ipilimumab combination therapy had been reported to result in increased expression of tumor endothelial cell adhesion molecules and increased intracellular immune cell infiltration in the treatment of advanced metastatic melanoma, which was furthermore related to clinical response (15). In RCC, combination studies using bevacizumab with the anti-PDL1 therapeutic, as well as sunitinib with nivolumab, have been reported $(16,17)$. Bevacizumab treatment has been shown to result 


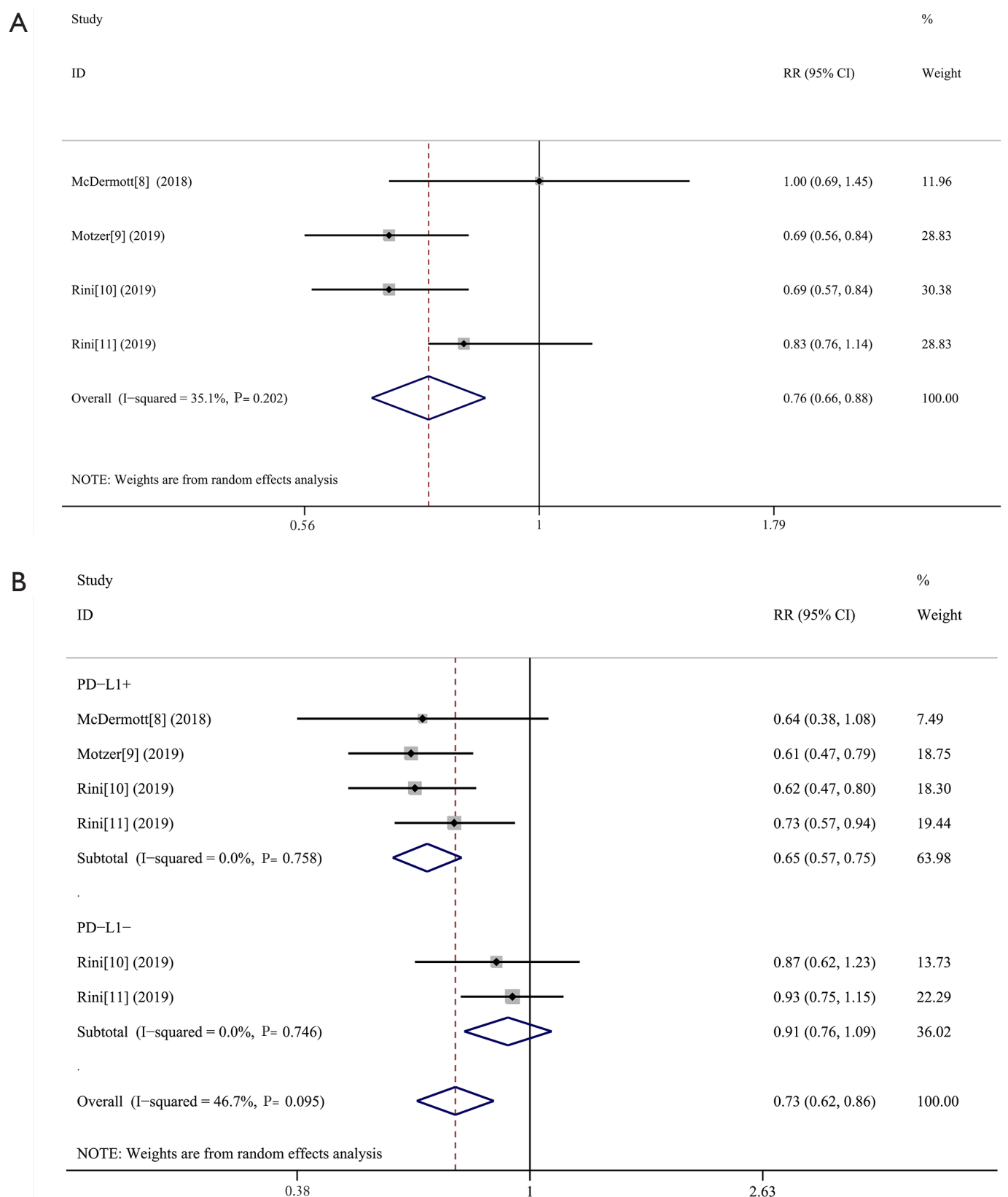

Figure 3 Meta-analysis of HRs for PFS comparing ICIs combined with anti-angiogenic drugs and sunitinib. (A) Unselected patients; (B) PD-L1 positive and negative patients. HR, hazard ratio; PFS, progression-free survival; ICIs, immune checkpoint inhibitors.

in increased intratumoral $\mathrm{T}$ cells, and $\mathrm{T}$ cell levels were further increased upon combination with MPDL3280A (18). Our study further demonstrates the efficacy of ICIs in combination with anti-angiogenic drugs for first-line treatment of mRCC.

Our study found that positive effects of ICIs combined with anti-angiogenic drugs are more pronounced in patients with positive PD-L1 expression. This raised the question where ICI efficacy may be related to PD-L1 expression. In our current study we found that approximately $40-50 \%$ of ccRCC cases had positive PD-L1 status (19-21). It has been reported that patients with PD-L1 overexpression have a poor prognosis, and a previous meta-analysis showed that PD-L1 expression is a negative prognostic factor in 


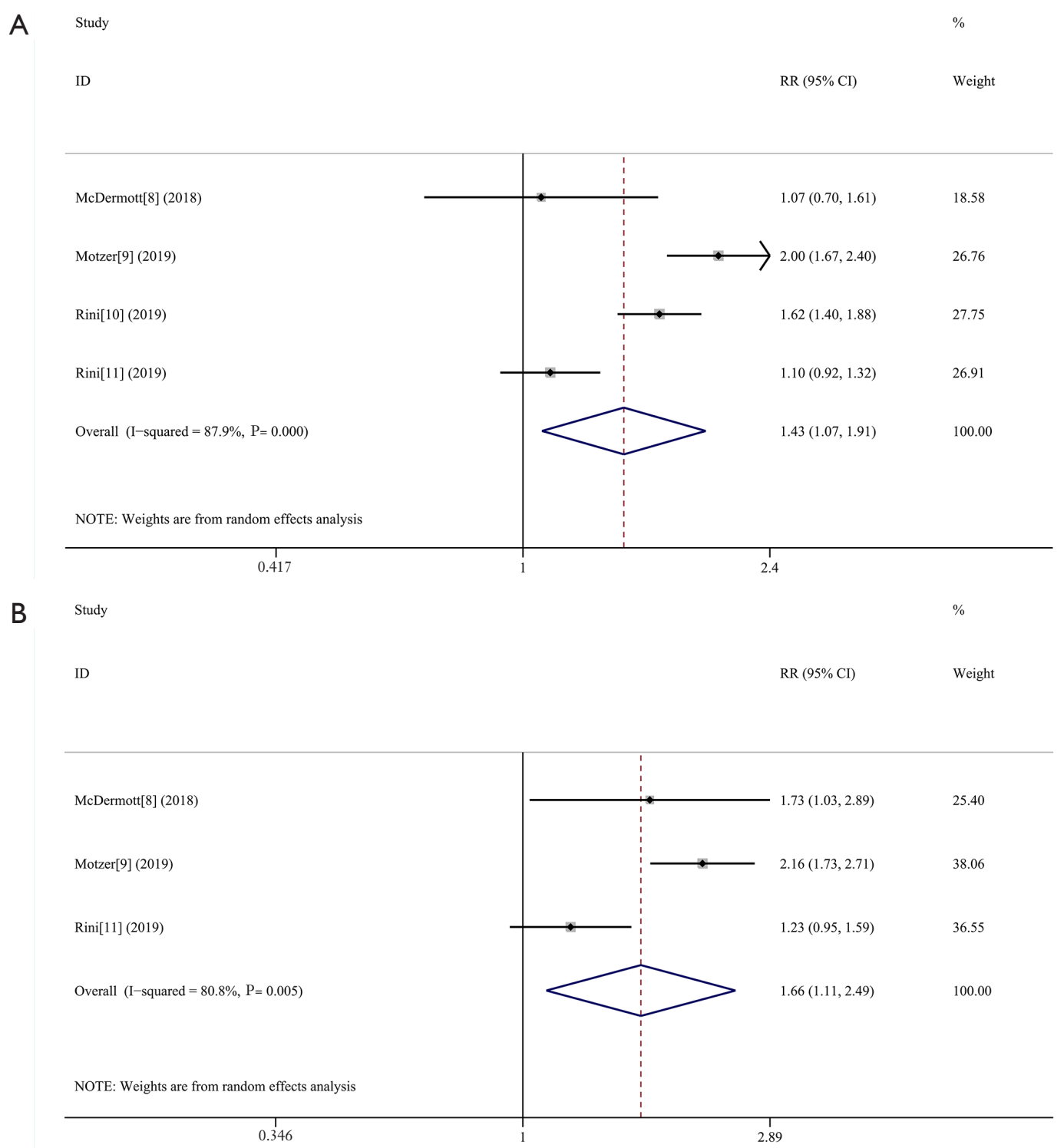

Figure 4 Meta-analysis of HRs for ORR comparing ICIs combined with anti-angiogenic drugs and sunitinib. (A) Unselected patients; (B) PD-L1 positive patients. HR, hazard ratio; ORR, objective response rate; ICIs, immune checkpoint inhibitors.

renal cancer. Furthermore, PD-L1 expression has also been associated more aggressive clinical features of tumors in RCC patients (22). Although PD-L1 status has been studied as a prognostic factor in several tumor types, its role as a predictive marker of response to therapy in patients treated with ICIs is unclear. A meta-analysis involving 20 trials and approximately 6,000 patients with different cancer types, including RCC, reported no significant difference in the response to treatment of RCC patients stratified by PDL1 status (23). In the CheckMate 025 study, PD-L1 status did not affect efficacy of nicurumab and everolimus (4).
Conversely, in the CheckMate 214 study, a beneficial effect of nivolumab and ipilimumab was observed on OS in moderate and low risk PD-L1 positive patients (9). A phase $\mathrm{Ib}$ trial assessing the use of axitinib and avemumab in mRCC showed that patients with PD-L1 $>1 \%$ had a higher ORR (24). These differences may be explained by the intratumoral heterogeneity of PD-L1 expression. PD$\mathrm{L} 1$ is generally assessed in the primary nephrectomy, but in about $20 \%$ of patients with metastatic renal cancer, PD-L1 staining shows a discrepancy between primary tumor and corresponding metastasis. Conversely, when only assessing 


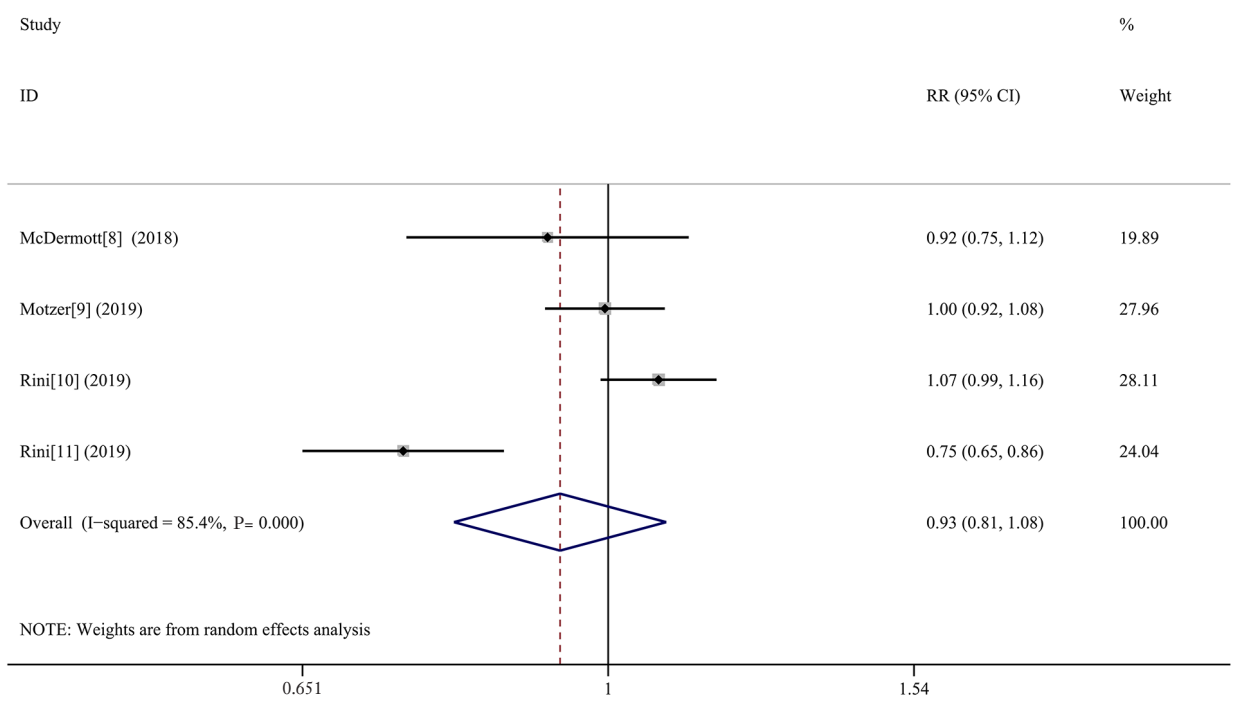

Figure 5 Meta-analysis of HRs for adverse events ( $\geq$ Grade 3 ) comparing ICIs combined with anti-angiogenic drugs and sunitinib. HR, hazard ratio; ICIs, immune checkpoint inhibitors.

Table 2 Adverse events ( $\geq$ Grade 3) comparing ICIs combined with anti-angiogenic drugs and sunitinib

\begin{tabular}{lc}
\hline Adverse events & $\%$ \\
\hline Motzer 2019 (9) & \\
Avelumab + Axitinib & 25.6 \\
Hypertension & 6.7 \\
Diarrhea & 6 \\
Increased alanine aminotransferase level & 5.8 \\
Palmar-plantar erythrodysesthesia syndrome & 3.9 \\
Increased aspartate aminotransferase level & 3.5 \\
Fatigue & 3 \\
Dyspnea & 2.8 \\
Decreased weight & 2.5 \\
Asthenia & 2.1 \\
Decreased appetite & \\
Sunitinib & 17.1 \\
Hypertension & 8.2 \\
Anemia & 8 \\
Neutropenia & 3.2 \\
Thrombocytopenia & 3.6 \\
Decreased neutrophil count & 5.7 \\
Decreased platelet count & 5.3 \\
Palmar-plantar erythrodysesthesia syndrome & \\
Fatigue & \\
Asthenia & \\
Diarrhea & \\
\hline
\end{tabular}

Table 2 (continued)
Table 2 (continued)

\begin{tabular}{|c|c|}
\hline Adverse events & $\%$ \\
\hline \multicolumn{2}{|l|}{ Rini 2019 (10) } \\
\hline \multicolumn{2}{|l|}{ Pembrolizumab + Axitinib } \\
\hline Hypertension & 22.1 \\
\hline Alanine aminotransferase increased & 13.3 \\
\hline Diarrhea & 9.1 \\
\hline Aspartate aminotransferase increased & 7 \\
\hline $\begin{array}{l}\text { Palmar-plantar erythrodysesthesia } \\
\text { syndrome }\end{array}$ & 5.1 \\
\hline Weight decreased & 3 \\
\hline Proteinuria & 2.8 \\
\hline Fatigue & 2.8 \\
\hline Asthenia & 2.6 \\
\hline Dyspnea & 1.6 \\
\hline \multicolumn{2}{|l|}{ Sunitinib } \\
\hline Hypertension & 19.3 \\
\hline Platelet count decreased & 7.3 \\
\hline Neutrophil count decreased & 6.8 \\
\hline Neutropenia & 6.6 \\
\hline Fatigue & 6.6 \\
\hline Thrombocytopenia & 5.9 \\
\hline Anemia & 4.9 \\
\hline Diarrhea & 4.7 \\
\hline Palmar-plantar erythrodysesthesia syndrome & 3.8 \\
\hline Alanine aminotransferase increased & 3.1 \\
\hline
\end{tabular}

ICls, immune checkpoint inhibitors. 
PD-L1 expression in tumor metastasis samples from the same patient, higher consistency was found (25).

However, several limitations should be acknowledged. First, the study is based on a meta-analysis of the literature rather than direct patient data. Second, our meta-analysis involved only a limited number of studies and these studies used different medications in experimental groups. Third, IMDC subgroups and geographical features could have been important confounding factors affecting the analysis. In addition, it should be mentioned that PD-L1 status assessments still suffer from shortcomings, such as intratumoral heterogeneity mentioned above.

\section{Conclusions}

Our meta-analysis reveals efficacy and safety of the combination of ICIs and anti-angiogenic drugs for first-line treatment for mccRCC patients. This therapeutic regimen can improve OS, PFS, ORR and ORR in mccRCC patients with positive PD-L1 status. Our analysis revealed that the combination of ICIs and anti-angiogenic drugs did not increase the incidence of adverse events However, more prospective studies are needed to further confirm these findings, as well as studies involving other types of renal cancer.

\section{Acknowledgments}

Funding: This meta-analysis has been financially supported by National Natural Science Foundation of China (No. 81672534).

\section{Footnote}

Reporting Checklist: The authors have completed the PRISMA reporting checklist. Available at http://dx.doi. org/10.21037/tau-20-969

Conflicts of Interest: All authors have completed the ICMJE uniform disclosure form (available at http://dx.doi. org/10.21037/tau-20-969). The authors have no conflicts of interest to declare.

Ethical Statement: The authors are accountable for all aspects of the work in ensuring that questions related to the accuracy or integrity of any part of the work are appropriately investigated and resolved. The data comes from the database, so ethical approval and informed consent are not required.

Open Access Statement: This is an Open Access article distributed in accordance with the Creative Commons Attribution-NonCommercial-NoDerivs 4.0 International License (CC BY-NC-ND 4.0), which permits the noncommercial replication and distribution of the article with the strict proviso that no changes or edits are made and the original work is properly cited (including links to both the formal publication through the relevant DOI and the license). See: https://creativecommons.org/licenses/by-nc-nd/4.0/.

\section{References}

1. Rini BI, Campbell SC, Escudier B. Renal cell carcinoma. Lancet 2009;373:1119-32.

2. Chen W, Zheng R, Baade PD, et al. Cancer statistics in China, 2015.CA Cancer J Clin 2016;66:115-32.

3. Iacovelli R, Sternberg $\mathrm{CN}$, Porta $\mathrm{C}$, et al. Inhibition of the VEGF/VEGFR pathway improves survival in advanced kidney cancer: a systematic review and meta-analysis. Curr Drug Targets 2015;16:164-70.

4. Motzer RJ, Escudier B, McDermott DF, et al. Nivolumab versus everolimus in advanced renal cell carcinoma. $\mathrm{N}$ Engl J Med 2015;373:1803-13.

5. Hughes PE, Caenepeel S, Wu LC. Targeted therapy and checkpoint immunotherapy combinations for the treatment of cancer. Trends Immunol 2016;37:462-76.

6. Atkins MB, Plimack ER, Puzanov I, et al. Axitinibin combination with pembrolizumab in patients (pts)with advanced renal cell carcinoma (aRCC): Preliminary safety and efficacy results. Ann Oncol 2016;27:266-95.

7. Wallin JJ, Bendell JC, Funke R, et al. Atezolizumabin combination with bevacizumab enhances antigen-specific T-cell migration in metastatic renal cell carcinoma. Nat Commun 2016;7:12624.

8. McDermott DF, Huseni MA, Atkins MB, et al. Clinical activity and molecular correlates of response to atezolizumab alone or in combination with bevacizumab versus sunitinib in renal cell carcinoma. Nature Med 2018;24:749-57.

9. Motzer RJ, Penkov K, Haanen J, et al. Avelumab plus axitinib versus sunitinib for advanced renal-cell carcinoma. N Engl J Med 2019;380:1103-15.

10. Rini BI, Plimack ER, Stus V, et al. Pembrolizumab plus axitinib versus sunitinib for advanced renal-cell carcinoma. 
N Engl J Med 2019;380:1116-27.

11. Rini BI, Powles T, Atkins MB, et al. Atezolizumab plus bevacizumab versus sunitinib in patients with previously untreated metastatic renal cell carcinoma (IMmotion151): a multicentre, open-label, phase 3, randomised controlled trial. Lancet 2019;393:2404-15.

12. Liberati A, Altman DG, Tetzlaff J, et al. The PRISMA statement for reporting systematic reviews and metaanalyses of studies that evaluate health care interventions: explanation and elaboration. PLoS Med 2009;6:e1000100.

13. Tarsilla M. Naunyn-Schmiedebergs Archiv für experimentelle Pathologie und Pharmakologie. Cochrane Handbook for Systematic Reviews of Interventions. Naunyn-Schmiedebergs Arch Exp Pathol Pharmakol 2011;5:S38.

14. Donini M, Buti S, Massari F, et al. Management of oligometastatic and oligoprogressive renal cell carcinoma: state of the art and future directions. Expert Rev Anticancer Ther 2020;20:491-501.

15. Hodi FS, Lawrence D, Lezcano C, et al. Bevacizumab plus ipilimumab in patients with metastatic melanoma. Cancer Immunol Res 2014;2:632.

16. Amin A, Ernstoff MS, Infante JR, et al. A phase I study of nivolumab (anti-PD-1; BMS-936558; ONO-4538) in combination with sunitinib, pazopanib, or ipilimumab in patients (pts) with metastatic renal cell carcinoma (mRCC). J Clin Oncol 2013;31:1904-11.

17. Lieu C, Bendell J, Powderly JD, et al. Safety and efficacy of MPDL3280A (anti- PDL1) in combination with bevacizumab (BEV) and/or chemotherapy (chemo) in patients (PTS) with locally advanced or metastatic solid tumors. Ann Oncol 2014;25:iv361.

Cite this article as: Xie Y, Chen Z, Zhong Q, Chen Y, Shangguan W, Xie W. Efficacy and safety of immunological checkpoint inhibitors combined with anti-angiogenic drugs in first-line treatment of metastatic renal cell carcinoma: a systematic review and meta-analysis. Transl Androl Urol 2021;10(1):300-309. doi: 10.21037/tau-20-969
18. Sznol M, Mcdermott DF, Jones SF, et al. Phase Ib evaluation of MPDL3280A (anti-PDL1) in combination with bevacizumab (bev) in patients (pts) with metastatic renal cell carcinoma (mRCC). J Clin Oncol 2015;33:410.

19. Xu F, Xu L, Wang Q, et al. Clinicopathological and prognostic value of programmed death ligand-1 (PD-L1) in renal cell carcinoma: a meta-analysis. Int J Clin Exp Med 2015;8:14595-603.

20. Leite KR, Reis ST, Junior JP, et al. PD-L1 expression in renal cell carcinoma clear cell type is related to unfavorable prognosis. Diagn Pathol 2015;10:189.

21. Zhang X, Yin X, Zhang H, et al. Differential expressions of PD-1, PD-L1 and PD-L2 between primary and metastatic sites in renal cell carcinoma. BMC Cancer 2019;19:360.

22. Wang Z, Peng S, Xie H, et al. Prognostic and clinicopathological significance of PD-L1 in patients with renal cell carcinoma: a meta-analysis based on 1863 individuals. Clin Exp Med 2018;18:165-75.

23. Gandini S, Massi D, Mandalà M. PD-L1 expression in cancer patients receiving anti PD-1/ PD-L1 antibodies: a systematic review and meta-analysis. Crit Rev Oncol Hematol 2016;100:88-98.

24. Choueiri TK, Larkin J, Oya M, et al. Preliminary results for avelumab plus axitinib as first-line therapy in patients with advanced clear-cell renalcell carcinoma (JAVELIN Renal 100): an openlabel, dose finding and dose-expansion, phase 1b trial. Lancet Oncol 2018;19:451-60.

25. Callea M, Albiges L, Gupta M, et al. Differential expression of PD-L1 between primary and metastatic sites in clear-cell renal cell carcinoma. Cancer Immunol Res 2015;3:1158-64. 